\title{
Proteção Social no Brasil: da seguridade social à transferência condicionada de renda 1
}

\author{
Social Protection in Brazil: From Social Security to Conditional Cash Transfer \\ Rosilaine Coradini Guilherme* \\ Carlos Nelson dos Reis**
}

\begin{abstract}
Resumo
Este texto versa sobre as peculiaridades da constituição do sistema de proteção social no Brasil mediante análise da particularidade sócio histórica que permeia esse território, o qual possui hiato temporal de um século em relação aos países europeus no reconhecimento da questão social. 0 recorte utilizado envolve o período de 1930 a 2015, com destaque para o Estado democrático e de direito consubstanciado na Constituição Federal de 1988, assim como a contrarreforma de fundamentação neoliberal iniciada nos anos 1990. Em específico serão desenvolvidas análises a respeito do Programa Bolsa Família, visando explicitar a tendência seletivista e fragmentada das políticas sociais. Ao final conclui-se que as reformas restritivas da proteção social com destaque para as políticas de seguridade social - representadas pela predominância dos programas de transferência condicionada de renda - configuram resposta do capital à sua "crise", o que contribui para a reprodução desse modo de produção, bem como para ampliação dos níveis de desigualdade social.
\end{abstract}

Palavras-chave: Proteção social. Seguridade social. Transferência condicionada de renda.

\begin{abstract}
This text deals about the peculiarities of the constitution of the system with social protection in Brazil by analyzing the socio-historical particularity that permeates this territory, which has a temporal gap of one century in relation to European countries in the recognition of the social question. The cut used involves the period from 1930 to 2015, with emphasis on the democratic and constitutional state embodied in the Federal Constitution of 1988, as well as the neoliberal counterreformation started in the 1990s. Specifically, analyzes will be developed regarding the Bolsa Familia Program, aiming to explain the selectivist and fragmented tendency of social policies. In the end, it is concluded that the restrictive reforms of social protection - represented by the preponderance of conditional cash transfer programs - constitute a response of capital to its "crisis", which contributes to the reproduction of this mode of production, as well as to increase levels of social inequality.
\end{abstract}

Keywords: Social protection. Social Security. Conditional transfer of income.

\footnotetext{
1As reflexões apresentadas são subprodutos da Tese de doutoramento intitulada "Renda mínima de inserção e transferência condicionada de renda: as (a) simetrias entre União Europeia e MERCOSUL", defendida no PPGSS/PUCRS, em março de 2016

* Assistente Social, Doutora em Serviço Social pela Pontifícia Universidade Católica do Rio Grande do Sul (PUCRS). Professora Adjunta na Universidade Federal do Pampa (UNIPAMPA), Curso de Serviço Social, Campus São Borja - RS/BR. Líder do grupo de pesquisa Trabalho, Formação Profissional em Serviço Social e Política Social na América Latina/ CNPq - Universidade Federal do Pampa. E-mail: rosilaineguilherme@yahoo.com.br

** Economista, Doutorado em Política Econômica pela Universidade Estadual de Campinas (UNICAMP). Professor Titular no Programa de Pós-Graduação em Serviço Social da Pontifícia Universidade Católica do Rio Grande do Sul (PUCRS), Porto Alegre-RS/BR. Líder do Grupo de Pesquisa em Economia do Bem-Estar Social - NEPES/CNPq (PPGSS-PUCRS). E-mail: cnelson@pucrs.br
} 


\section{Introdução}

O Brasil, inserido no continente latino-americano e, mais especificamente, no Mercado Comum do Sul - MERCOSUL, desde a sua "descoberta" e colonização por Portugal encontra-se subordinado, em nível econômico e tecnológico, aos países com economias avançadas. Tal fato define as origens de um crescimento econômico considerado de menor escala e de uma formação social que envolve processos como a colonização, a escravidão e regimes ditatoriais. Além dessas particularidades de ordem estrutural há de se ponderar, em termos históricos, que o advento de um sistema de proteção social ainda é recente no Brasil, pois se estabelece - no sentido formal - com a Constituição Federal de 1988, considerada um avanço ao campo dos direitos sociais.

Essa incipiência agrava de maneira mais intensa os níveis de desigualdade social e pobreza, apreendida na sua concepção muldimensional e estrutural, para além da carência monetária. Entretanto, a partir dos anos 1990 "o que se observa é que os programas de transferência de renda focalizados na pobreza e na extrema pobreza revelam, sob a orientação da ideologia neoliberal, profundas mudanças nas politicas sociais contemporâneas" (YAZBEK, 2012, p. 310). Certamente, a focalização figura entre os principais limites desses programas, na medida em que representa uma reorientação do conquistado sistema de proteção social, fundado no princípio universalista e na concepção de cidadania ampliada.

Entende-se que as mudanças restritivas do padrão da proteção social se encontram alinhadas ao paradigma neoliberal, o qual sustenta a atual formulação da política econômica e social impulsionando severas repercussões na América Latina. No Brasil, as reformas de primeira geração afirmadas no Consenso de Washington em 1989 - disciplina orçamentária, liberalização financeira, privatizações, etc - foram implantadas a partir dos anos 1990, o que converge com o processo de desmonte - pela via da austeridade fiscal - das políticas sociais de cunho universal.

A partir dessa linha reflexiva introdutória, o presente artigo objetiva discorrer brevemente a respeito das peculiaridades da constituição do sistema de proteção social no Brasil, com destaque para a conquista da seguridade social, assim como também pretende abordar o principal programa de transferência de renda brasileiro nomeado de Bolsa Família, 
a fim de explicitar a predominância deste em detrimento as demais políticas que compõem o sistema de seguridade social.

Para tanto, ancora-se em uma pesquisa exploratória - a íntegra da referida pesquisa encontra-se sistematizada em Guilherme (2016) - na qual o acesso aos dados ocorreu mediante fontes de base documental, utilizando como suporte levantamento bibliográfico que teve como recorte a produção científica da área das ciências sociais e humanas vinculadas a teoria social crítica.

Sendo assim, o artigo se estrutura em duas perspectivas: inicialmente apresenta-se uma análise da constituição de um sistema de proteção social no Brasil, com destaque para a particularidade sócio-histórica e as tendências contemporâneas no âmbito das políticas sociais; e, na sequência aprofunda-se sobre essas tendências contemporâneas - seletividade e focalização - a partir da experiência brasileira de implementação do Programa Bolsa Família -PBF. Ao final, são mencionadas algumas considerações no intuito de se colocar em pauta o combate das desigualdades, sob ponto de vista estrutural, o que corresponde ao processo de mudanças na orientação das políticas econômicas, ou seja, inverter a prevalência do econômico sobre o social.

\section{A Proteção Social no Brasil: particularidade sócio-histórica e tendências contemporâneas}

Com hiato temporal de um século em relação aos países europeus, o reconhecimento da questão social pelo Estado brasileiro ocorre na Era Vargas, precisamente no primeiro ano desse governo em 1930, cuja marca predominante é a execução de uma proteção social voltada à reprodução da força de trabalho, especificamente destinada à população que possui relação contratual de trabalho. Entretanto, importante referir que já no início do século XX, a partir da consolidação do mercado de trabalho no contexto da industrialização e urbanização, a consciência e a organização de classe dos trabalhadores livres assalariados se fortalecem mediante instituição da representação sindical.

A passagem para o século XX foi sacudida pela transformação dos primeiros sindicatos, na agricultura e nas indústrias rurais a partir de 1903, dos demais trabalhadores urbanos a partir de 1907, quando é reconhecido o direito de organização sindical. Esse processo se dá sob forte influência dos imigrantes que traziam os ares dos movimentos anarquistas e socialistas europeus para o país [...]. O ano de 1923 é chave para a compreensão do formato da política social brasileira no período subsequente: aprova-se a Lei Eloy Chaves, que institui a obrigatoriedade 
de criação de Caixas de Aposentadorias e Pensões (CAPs) para algumas categorias estratégicas de trabalhadores, a exemplo dos ferroviários e marítimos (BEHRING; BOSCHETTI, 2007, p. 80).

Em decorrência, especificamente no governo Vargas há o reconhecimento da questão social ${ }^{2}$, embora ao mesmo tempo decorra o empenho em conter os processos de resistências da classe trabalhadora, principalmente por meio de políticas sociais com corte de acesso restrito a algumas categorias profissionais urbanas estratégicas no sistema produtivo e no processo de comercialização da produção, como os marítimos e os ferroviários - portanto não se tratava de direitos sociais de cunho universal. De fato, "é na correlação de forças sociais que a política social se estabelece e se modifica, a partir das transformações das relações de apropriação econômica, como também do exercício da dominação política." (SPOSATI et al., 1998, p. 33).

É desse período a instauração do salário mínimo, o qual é considerado como a primeira iniciativa de mínimos sociais, implantado em 1940, com a ressalva de que essa renda mínima somente se estende aos trabalhadores com vínculo contratual formal de trabalho (SILVA; YAZBEK; DI GIOVANNI, 2004). Em estudo realizado por Reis (2004) dos direitos sociais constituídos entre 1930-1988 em cinco áreas incluindo a previdência e a assistência social, figura a Renda Mensal Vitalícia-RMV, criada em 1974, no âmbito do Ministério da Previdência e Assistência. Destinada às pessoas com mais de 70 anos ou 'inválidos' sem meios para prover a subsistência, a RMV representa um mínimo social com caráter assistencial, embora estabeleça, entre outros critérios, a filiação previdenciária mínima de doze meses. Daí a importância do Benefício de Prestação Continuada - BPC - o qual substitui o RMV - pois representa uma transferência monetária para idosos e pessoas com deficiência sem meios de prover a subsistência e nem tê-la provida por sua família, cuja renda familiar mensal per capita deve ser inferior a $1 \frac{1}{4}$ do salário mínimo.

O BPC é afiançado pela Constituição Federal de 1988 e regulamentado na Lei Orgânica de Assistência Social - LOAS - 8.742/1993 (BRASIL, 1993), no domínio da política de assistência social que, a partir desse marco constitucional integra o tripé da seguridade social juntamente com as políticas de saúde e da previdência social, incorporando o status de política pública não contributiva. A assistência social, no art. 1ำ da LOAS, é definida como

\footnotetext{
2“A gênese da questão social na sociedade burguesa deriva do caráter coletivo da produção contraposto à apropriação privada da própria atividade humana - o trabalho - das condições necessárias à sua realização, assim como de seus frutos." (IAMAMOTO, 2008, p. 156).
} 
direito do cidadão e dever do Estado no âmbito da seguridade social, no sentido de prover os mínimos sociais e o atendimento às necessidades básicas, mediante conjunto integrado de ações e de iniciativas pública e da sociedade. Entretanto, cabe referir que a ausência da definição conceitual acerca dos mínimos sociais pela LOAS é discutida pela literatura especializada como campo propício às interpretações das mais distintas correntes teóricas, sendo necessário estabelecer parâmetros que a sustente como direito de cidadania (BRASIL, 2009). Nesse sentido, compartilha-se à ideia de que isso implica "considerar a provisão social como uma política em movimento, que não se contenta em procurar suprir, de forma isolada e estática, nem ínfima ou mesmo basicamente, privações e carências críticas que, por serem 'máximas' ou extremas, exigem respostas mais complexas e substanciais." (PEREIRA, 2000, p. 27). Além disso, importante destacar que a proteção social quando exercida pela esfera estatal,

[...] é socialmente assumida como função do poder público e representa a existência de um conjunto de garantias, mais ou menos extensas, através de intervenção política e administrativa. Mas a existência e a constituição de sistemas de proteção social desta natureza não excluem a persistência ou a constituição de outras formas de proteção social, privadas, nas quais o alcance dos mesmos objetivos está confiado a acordos entre sujeitos, seja na base de relações mercantis ou fundada em vínculos tradicionais (DI GIOVANNI, 1998, p. 12-13).

Em termos históricos, o final dos anos 1980 comporta expressivas conquistas da classe trabalhadora pela via da resistência política e confluência de diversos movimentos sociais com o fim da ditatura militar iniciada em 1964 e a instauração do Estado democrático e de direito, consubstanciado pela Constituição Federal de 1988 que prevê mudança qualitativa na concepção de proteção social vigente, pois estabelece importantes direitos sociais, além de introduzir o princípio da universalidade e da criação de um sistema de seguridade social. De maneira concomitante, impõem-se fatores macroeconômicos e políticos adversos a materialização desses direitos constituídos juridicamente, expressando a coexistência de propostas distintas. Isto é, a reforma do Estado materializada pela Constituição Federal de 1988 e a contrarreforma do Estado com a adesão já no início dos anos 1990, pelo país, às medidas de ajuste estrutural que inclui, nos termos tratados pela literatura, a privatização, a focalização e a descentralização das políticas sociais, com a prevalência de políticas econômicas que se sustentam no paradigma teórico neoliberal. 


\begin{abstract}
A tendência geral tem sido a de redução de direitos, sob o argumento da crise fiscal do Estado, transformado as políticas sociais - a depender da correlação de forças entre as classes sociais e segmentos de classes e do grau de consolidação da democracia e da política social nos países - em ações pontuais e compensatórias direcionadas para efeitos mais perversos da crise. As possibilidades preventivas e até eventualmente redistributivas tornam-se mais limitadas, prevalecendo o já referido trinômio articulado do ideário neoliberal para as políticas sociais, qual seja: a privatização, a focalização e a descentralização (BEHRING; BOSCHETTI, 2007, p. 156).
\end{abstract}

Daí surge diversas medidas emergências de combate à pobreza em razão da ampliação dos níveis de desigualdade social decorrentes do processo de ajuste estrutural. Essas têm como propósito atingir as camadas sociais que não contribuem com a previdência social - portanto sem vínculo formal laboral - e também não se enquadram nos restritivos critérios monetários impostos para acesso ao BPC. Em relação ao enfrentamento da pobreza, tem-se, especificamente no art. 25 da LOAS, a regulamentação Dos Projetos de Enfrentamento da Pobreza, os quais são qualificados como investimento econômico-social nos grupos populares, no sentido de subsidiar recursos técnicos e financeiros às iniciativas que Ihes garantam meios, capacidade produtiva e de gestão para melhoria das condições gerais de subsistência. Entretanto, o incentivo a tais projetos, nos termos do Art. 26, deve assentar-se em mecanismos de articulação e participação de diferentes áreas governamentais e em sistema de cooperação entre organismos governamentais, não governamentais e da sociedade civil.

O fato é que, na prática, abre-se lacuna à implementação das políticas neoliberais pela via da transferência de responsabilidade pelo Estado ao terceiro setor como a proliferação das Organizações Não Governamentais - ONGs, do voluntariado e de campanhas de cunho solidário promovido pelo setor empresarial na linha da responsabilidade social. Uma forma específica dessa tendência - no governo do presidente Fernando Henrique Cardoso em 1995 - é o "Programa Comunidade Solidária, cuja marca era a focalização conservadora que se orientava pela concentração do combate à pobreza apenas em alguns municípios brasileiros, considerados os mais miseráveis", bem como "pelo alijamento do movimento social, embora seja conclamada a participação da sociedade civil na luta contra a pobreza" (SILVA; YAZBEK; DI GIOVANNI, 2004, p. 91). Importante referir que o trato à pobreza no país, se baseia amplamente nas recomendações de agências multilaterais, sobretudo a partir dos anos 2000 com adesão à agenda social da Organização das Nações Unidas-ONU ou Metas do Milênio que tem como foco a erradicação da fome e da extrema pobreza. O que corresponde à prevalência de políticas sociais focalizadas e da responsabilização do núcleo familiar e/ou 
comunidade/sociedade civil no campo da proteção social, na medida em que o Estado somente intervém quando o indivíduo não possuir meios para prover a própria subsistência ou tê-la provida pela família. Essa minimização por parte do Estado e a maximização do núcleo familiar no campo da proteção social é tratada, pela literatura, como Estado familista ou pluralismo de bem-estar social. Sobre o tema há que:

[...] a família alça um lugar central tanto no âmbito dos programas de Transferência de Renda, que marca essa centralidade no seu próprio nome - Bolsa Família - como no campo das políticas públicas que compõem o tripé da seguridade social, particularmente saúde e assistência social. Na política de saúde, o Programa Saúde da Família é criado em 1994 e incorporado, em 2006, como Estratégia no âmbito da Política Nacional de Atenção Básica. Na política de assistência social assume-se a matricialidade sócio familiar inicialmente como princípio e, posteriormente, como diretriz do Sistema Único de Assistência Social (SUAS) (MIOTO, 2008, p. 144).

Embora o programa de transferência de renda nomeado de Bolsa Família esteja em desenvolvimento no Brasil desde 2003, o marco inicial dessas iniciativas data em 1991, mediante Projeto de Lei de autoria do Senador Eduardo Suplicy - Programa de Garantia de Renda Mínima-PGRM - o qual viabilizou a implantação de experiências pioneiras, porém em escala geográfica restrita as cidades de Campinas, Brasília, Ribeirão Preto e Santos (SILVA; YAZBEK; DI GIOVANNI, 2004). Em nível nacional, a partir desse marco, tem-se que o debate acerca dos Programas de Transferência Condicionada de Renda - PTCR "se aprofundou durante a década de 1990, passando a se constituir, nesse inicio do século XXI, o que já se pode considerar a estratégia principal no eixo da Política de Assistência Social do Sistema Brasileiro de Proteção Social na atualidade" (SILVA; YAZBEK; DI GIOVANNI, 2004, p. 33). Nesse sentido, a partir do conjunto de informações e reflexões desenvolvidas na presente seção, no próximo item busca-se colocar em questão as particularidades e decorrentes evidências práticas do programa brasileiro Bolsa Família.

\section{Programa Bolsa Família: as evidências práticas da experiência brasileira}

No ano de 2009 o Programa Bolsa Família, instituído em 2004 pela Lei № 10.836 (BRASIL, 2017), "já abrangia todos os 5.563 municípios brasileiros e o Distrito Federal e atendia 12.370.915 famílias pobres e extremamente pobres" (LIMA, 2010, p. 40). Isso significa que o programa configura uma política com abrangência territorial plena, embora focalizada nas 
famílias em situação de extrema pobreza e pobreza, cujas linhas correspondem, no início de 2016, aos seguintes intervalos, respectivamente: renda familiar per capita de R\$ 0,00 - R\$ 77,00; renda familiar per capita $\mathrm{R} \$ 77,01-\mathrm{R} \$ 154,00$. Chama atenção o nível desta linha de corte para a extrema pobreza, pois em 2016 significava 5,9 vezes menos do que o valor médio da cesta básica na cidade de São Paulo, seria esta a linha de corte necessária para interromper o vigoroso ciclo intergeracional da extrema pobreza brasileira?

No website do MDS são referidos três eixos que estruturam o programa: complemento de renda, a fim de garantir alívio mais imediato da pobreza; acesso a direitos educação, saúde e assistência social - no sentido de interromper o ciclo intergeracional da pobreza; articulação com outras ações e políticas sociais, visando o desenvolvimento das famílias para que elas superem a situação de vulnerabilidade e pobreza. Na Portaria № 251/2012 (BRASIL, 2017) que regulamenta a gestão das condicionalidades do PBF, especificamente nas considerações apresentadas pela então Ministra de Estado - MDS, Tereza Campello, há que a determinação de obrigações à permanência no programa visa ampliar o acesso das famílias às políticas de saúde, educação e assistência social, no sentido de impactar nas suas condições de vida, além de fortalecer a capacidade de o Poder Público oferecer tais serviços.

Sobre as penalidades em casos de descumprimento das condicionalidades - art. 3 são apresentadas como gradativas na medida em que se moldam ao histórico da família, podendo ser desde advertência, como bloqueio por um mês do benefício, até a suspensão das prestações por dois meses ou o seu cancelamento. Entende-se que as condicionalidades, tratadas institucionalmente como sinônimo de garantia do acesso aos direitos sociais, além das penalidades quando do seu descumprimento, são potencialmente segmentadoras e estigmatizantes, na medida em que submetem os beneficiários ao cumprimento de obrigações, em troca do benefício, mesmo que esses sejam direitos garantidos constitucionalmente como a saúde, a educação, o trabalho e a assistência social.

Esse paradoxo remete às antigas Leis dos Pobres $^{3}$, descaracterizando a perspectiva de cidadania ampliada, bem como não problematiza questões fundamentais: a ausência da renda do trabalho - gerada estruturalmente e não conjunturalmente - não decorre de suposta incapacidade intelectual e/ou técnica dos indivíduos; a evasão escolar não representa

\footnotetext{
${ }^{3}$ Para aprofundar o tema ver obra de Polanyi (2000), intitulada "A grande transformação: as origens da nossa época."
} 
uma escolha pessoal, pois em ampla medida é imposta por inúmeros fatores socioeconômicos de natureza estrutural; a precariedade e/ou inexistência de bens e serviços sociais públicos, os quais se convertem em obrigações, são impedimentos concretos ao acesso para toda a população. Desse modo, a fim de explicitar o conjunto das condicionalidades, além de outras dimensões que estruturam o PBF, como objetivos básicos, critérios à elegibilidade, benefícios monetários, sistematizou-se algumas informações, apresentadas no Quadro 1.

Quadro 1 - Síntese da Estrutura Básica do Programa Bolsa Família 2015 - Brasil

\begin{tabular}{|c|c|c|}
\hline País & Denominação & Bolsa Família \\
\hline & Objetivos Básicos & $\begin{array}{l}\text { Promover o acesso à rede de serviços, em especial de educação, saúde e } \\
\text { assistência social; combater a fome e promover a segurança alimentar e } \\
\text { nutricional; estimular o desenvolvimento das capacidades das famílias } \\
\text { em pobreza e indigência; combater a pobreza; e promover a } \\
\text { intersetorialidade, a complementariedade e a sinergia das ações sociais } \\
\text { do Poder Público. }\end{array}$ \\
\hline & $\begin{array}{c}\text { Regras } \\
\text { de elegibilidade }\end{array}$ & $\begin{array}{l}\text { opossuir informações cadastrais válidas e atualizadas, conforme } \\
\text { regulamento do Cadúnico; } \\
\text { oapresentar renda mensal per capita familiar igual ou inferior ao limite } \\
\text { definido para a situação de pobreza; } \\
\text { o ter crianças e/ou adolescentes de zero a dezessete anos incluídos no } \\
\text { Cadúnico, na hipótese da renda mensal per capita familiar estar entre os } \\
\text { limites de pobreza e de extrema pobreza. }\end{array}$ \\
\hline Brasil & Condicionalidades & $\begin{array}{l}\text { 1) Educação: } \\
\text { - Crianças ou adolescentes de } 6 \text { a } 15 \text { anos de idade, a matrícula e a } \\
\text { frequência mínima de } 85 \% \text { da carga horária escolar mensal; } \\
\text { - Adolescentes de } 16 \text { e } 17 \text { anos de idade, cujas famílias recebam o } \\
\text { Benefício Variável Vinculado ao Adolescente - BVJ, a matrícula e a } \\
\text { frequência mínima de } 75 \% \text { da carga horária escolar mensal; } \\
\text { 2) Saúde: } \\
\text {-Gestantes e nutrizes, o comparecimento às consultas de pré-natal e a } \\
\text { assistência ao puerpério, visando a promoção do aleitamento materno e } \\
\text { dos cuidados gerais com a alimentação e a saúde da criança; } \\
\text { - Crianças menores de } 7 \text { anos, o cumprimento do calendário de vacinação } \\
\text { e o acompanhamento do crescimento e do desenvolvimento infantil; } \\
\text { 3) Assistência social: } \\
\text { - Crianças e adolescentes de até } 15 \text { anos, em risco ou retiradas do } \\
\text { trabalho infantil, a frequência mínima de } 85 \% \text { da carga horária relativa } \\
\text { aos Serviços de Convivência e Fortalecimento de Vínculos - SCFV. }\end{array}$ \\
\hline
\end{tabular}

\begin{tabular}{|c|c|c|}
\hline Brasil & $\begin{array}{l}\text { Benefícios } \\
\text { monetários }\end{array}$ & $\begin{array}{l}\text { 1) Benefício Básico - no valor de } R \$ 77,00 \text { - destinado às unidades } \\
\text { familiares em situação de extrema pobreza (renda mensal per capita de } \\
\text { até } R \$ 77,00 \text { ). } \\
\text { 2) Benefícios Variáveis - no valor de } R \$ 35,00 \text { cada um (até cinco por } \\
\text { família) - destinados a unidades familiares em situação de pobreza e } \\
\text { extrema pobreza e que tenham em sua composição gestantes, nutrizes, } \\
\text { crianças de } 0 \text { e } 12 \text { anos ou adolescentes até } 15 \text { anos: }\end{array}$ \\
\hline
\end{tabular}




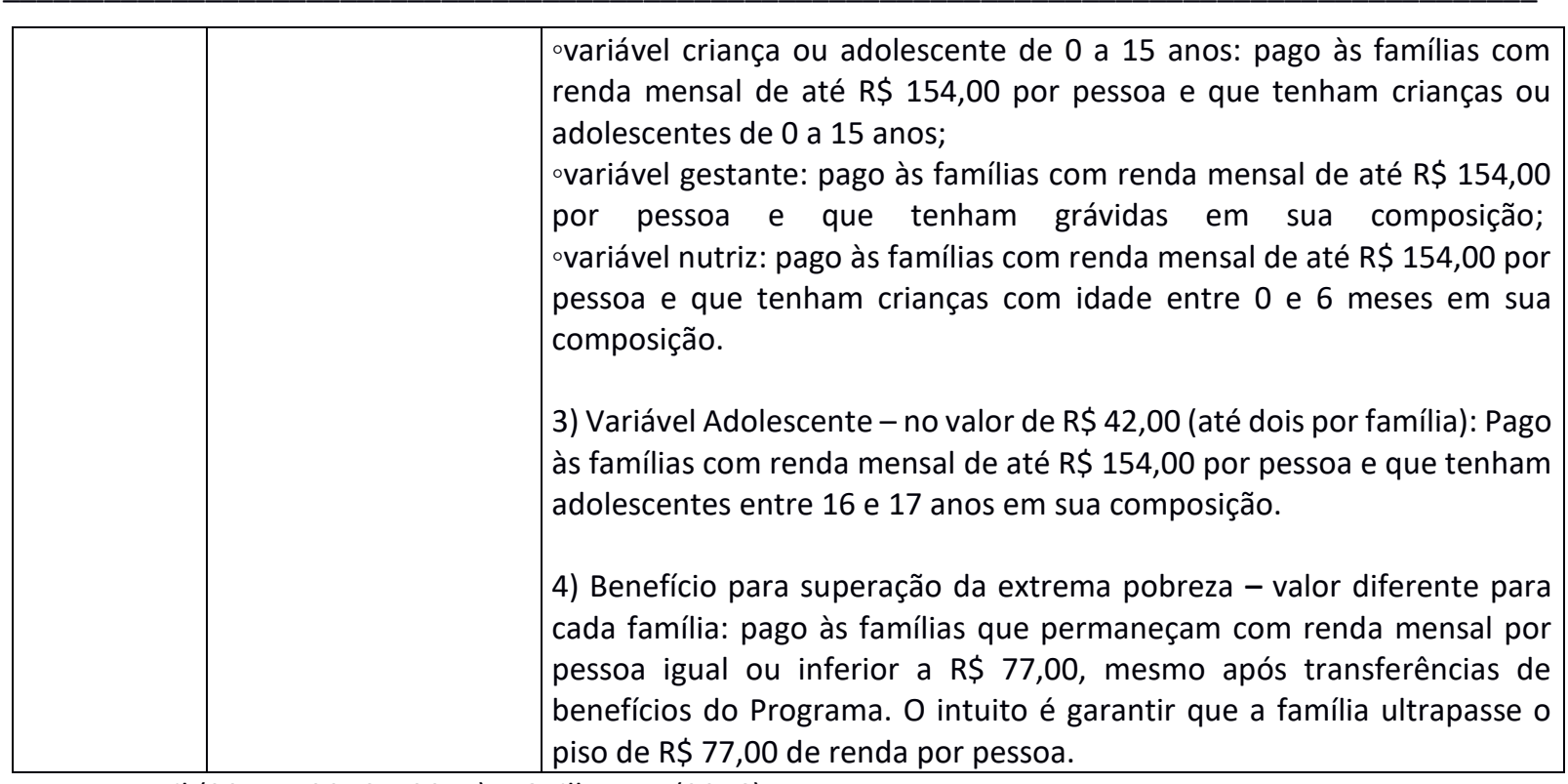

Fontes: Brasil (2015a, 2016a, 2017) e Guilherme (2016).

Sobre os benefícios monetários apresentados no Quadro 1, tem-se que os montantes são personalizados ou heterogêneos, pois variam conforme a composição familiar; a soma dos rendimentos brutos auferidos pelo agregado familiar; a faixa etária; e situações específicas como gestantes e nutrizes. No âmbito do programa, nos termos definidos na Lei 10.836/2004, é considerada a unidade nuclear, eventualmente ampliada por outros indivíduos que com ela possuam laços de parentesco e afinidade vivendo sob o mesmo teto e em economia comum, sendo a titularidade preferencialmente atribuída à mulher. No detalhe dos montantes, apesar de se ter clareza e de ser incontestável a importância dessas transferências monetárias no sentido de prover a subsistência de amplo contingente populacional cabe comentar os baixos níveis disponibilizados de forma categorial, como os benefícios variáveis - $R \$ 35,00$ - que se limitam, em termos cumulativos, a cinco por família. De forma articulada as transferências monetárias prevêem

[...] ações de caráter complementar, além da prioridade em inserir os beneficiários em outros programas dos governos locais e federal, com destaque à capacitação e inserção social, em programas de habitação, educação e saúde e em programas de taxas especiais de consumo de energia, telefone e água, entre outros (SILVA, 2014, p. 117).

Entre os limites impostos para se ultrapassar a tendência seletivista e fragmentada das políticas sociais, figuram as regras gerais de elegibilidade adotadas pelo PBF, cuja prevalência é a renda monetária. Cabe destacar que mesmo preenchendo os requisitos - nos termos do Decreto № 5.209/2004, art. 21, não há direito adquirido, o que significa que o PBF 
é uma política de governo e não uma política de Estado, em vista das prestações terem caráter temporário, devendo as famílias a cada dois anos se submeterem a novos testes de meios comprobatórios de pobreza. Outro aspecto limitador é que a concessão do beneficio está atrelada à estimativa do município correspondente, isto é, o número de famílias já incluídas em relação à estimativa de famílias pobres pelo mesmo município (BRASIL, 2016b). Para entender os impactos desse limitador cabe relacioná-lo aos dados nacionais publicados em janeiro de 2016 pelo Ministério de Desenvolvimento Social e Combate à Fome - MDS no Relatório de Informação (BRASIL, 2016b) sobre o Bolsa Família e Cadastro único-Cadúnico. Nos termos apresentados no Relatório, em novembro de 2015 havia 27.150.567 famílias 80.607.912 pessoas - inscritas no Cadúnico. Esse sistema cadastral reúne informações socioeconômicas das famílias de baixa renda, no intuito de selecioná-las para diversos programas (Tabela 1).

Tabela 1 - Bolsa família e Cadastro Único: intervalos de renda, famílias e pessoas cadastradas e percentual dos beneficiários de acordo com o intervalo de renda em $11 / 2015$

\begin{tabular}{c|c|c|c}
\hline $\begin{array}{c}\text { Renda familiar } \\
\text { (per capita R\$) }\end{array}$ & $\begin{array}{c}\text { No Famílias cadastradas } \\
\text { (CadÚnico 11/2015) }\end{array}$ & $\begin{array}{c}\text { No Pessoas cadastradas } \\
\text { (CadÚnico 11/2015) }\end{array}$ & $\begin{array}{c}\text { No Pessoas cadastradas } \\
\text { \% Total Pop. }\end{array}$ \\
\hline 0,00 até 77,00 & 12.316 .479 & 38.916 .569 & 20,40 \\
\hline 77,01 e 154,00 & 4.260 .693 & 14.654 .034 & 10,16 \\
\hline 154,01 e 1/2 SM & 6.296 .949 & 19.381 .061 & 4.01 \\
\hline Acima 1/2 SM & 4.276 .446 & 7.656 .248 & - \\
\hline Total & 27.150 .567 & 80.607 .912 & \\
\hline
\end{tabular}

Fonte: Brasil (2016b), Guilherme (2016).

Nota: para o cálculo do \% de pessoas cadastradas em relação ao total populacional utilizou-se Censo 2010 (190.732.694).

No início de 2016 no domínio do PBF, 13.969.391 famílias foram contempladas com o benefício, cujos valores médios das prestações pecuniárias apresentados são de R\$ 161,26. Nesse universo de famílias contempladas, estão inseridos grupos populacionais tradicionais e específicos como famílias quilombolas, indígenas, ciganas, pertencentes a comunidades de terreiros, assentadas da Reforma Agrária, de agricultores familiares, entre outros. O fato é que quando se compara o total de famílias contempladas pelo programa-13.969. 391 - com o da soma do total de famílias pobres (4.260.693) e extremamente pobres (12.316.479) cadastradas no Cadúnico como apresentado na Tabela 1 (16.580.542) explicita-se uma 
diferença negativa, o que corresponde à parcela sem acesso ao benefício. Mesmo ponderando que esse sistema cadastral não se restringe ao PBF, trata-se de famílias/pessoas que declararam renda mensal per capita - linha da pobreza e extrema pobreza - convergente aos critérios definidos para ser elegível ao programa. Isso representa aspectos fundamentais a serem ponderados, pois além de prevalecer critério unidimensional para caracterizar as linhas da pobreza e da extrema pobreza e, consequentemente, da determinação do acesso ao PBF, também existe hiato em termos de provisão.

Em Cartilha do MDS sobre o PBF há que "a concessão de benefícios é feita com base nas informações do Cadastro Único. O processo é automatizado e prioriza famílias com menor renda" (BRASIL, 2015b, p. 9). A prática de seleção dos mais pobres entre os pobres além de representar a subordinação da política social à econômica, também pode significar, numa suposição, a permanência no estado de pobreza, considerando a priorização da focalização à extrema pobreza, em detrimento à superação da pobreza. Tal fato alude à opinião do assessor especial da secretária geral da ONU para as Metas de Desenvolvimento do Milênio: "a meta é acabar com a pobreza extrema, não com toda a pobreza, e ainda menos, equiparar as rendas mundiais ou acabar a distância entre ricos e pobres. Isso pode acabar acontecendo, mas para tanto, os pobres terão que ficar ricos graças ao próprio esforço" (SACHS, 2005, p. 332).

Cabe lembrar que desde 2012 o PBF incorpora benefício para a superação da extrema pobreza, o qual cobre a diferença entre a renda familiar per capita e o valor da linha de pobreza extrema. Nos termos tratados na base de dados da CEPAL, esse novo componente fue extendido em 2013 a todos los hogares beneficiários do Bolsa Família, aunque estos no tengan hijos (CEPAL, 2015). Como destacado, considerando o recorte temporal do estudo, o benefício para superação da extrema pobreza, é pago às famílias que permaneçam com renda mensal per capita igual ou inferior a $\mathrm{R} \$ 77,00$, mesmo após transferências de benefícios do PBF. O intuito é garantir que a família ultrapasse $R \$ 77,00$ de renda por pessoa e, assim, supere a linha da extrema pobreza.

Em produção de Lima (2010) encontra-se ampla análise sobre os impactos do PBF, seja no âmbito das taxas de pobreza como das taxas de frequência escolar. As autoras mencionam que "os PTCR vêm contribuindo, no Brasil, para a redução dos índices de desigualdade e pobreza, principalmente para a redução da pobreza extrema, minorando as privações de vida das famílias, mas são insuficientes para tirá-las da pobreza, na maioria dos casos" (LIMA, 2010, p. 92-93). Cabe ainda atentar, como apresentado na Tabela 2, no detalhe 
da evolução da cobertura pessoas (\% total da população), que desde $2006,1 / 4$ da população total do país, em média, recebe o Bolsa Família.

Tabela 2 - Programa Bolsa Família: gastos em relação ao PIB, cobertura de famílias e pessoas e percentual de cobertura em relação ao total da população.

\begin{tabular}{l|c|c|c|c}
\hline Ano & $\begin{array}{c}\text { Despesas } \\
\text { executadas } \\
\text { (\% PIB) }\end{array}$ & $\begin{array}{c}\text { Cobertura famílias } \\
\text { (milhões) }\end{array}$ & $\begin{array}{c}\text { Cobertura } \\
\text { Pessoas } \\
\text { (milhões) }\end{array}$ & $\begin{array}{c}\text { Cobertura } \\
\text { Pessoas } \\
\text { (\% Total População) }\end{array}$ \\
\hline 2003 & 0,17 & 3.600 .000 & 16.560 .000 & 9,11 \\
\hline 2004 & 0,29 & 6.571 .839 & 30.230 .459 & 21,50 \\
\hline 2005 & 0,30 & 8.700 .445 & 40.022 .047 & 26,23 \\
\hline 2006 & 0,34 & 10.965 .810 & 49.346 .145 & 25,57 \\
\hline 2007 & 0,34 & 11.043 .076 & 48.589 .534 & 23,67 \\
\hline 2008 & 0,35 & 10.557 .996 & 45.399 .383 & 26,86 \\
\hline 2009 & 0,37 & 12.370 .915 & 51.957 .843 & 26,85 \\
\hline 2010 & 0,36 & 12.778 .220 & 52.390 .702 & 27,86 \\
\hline 2011 & 0,39 & 13.352 .306 & 54.744 .455 & 28,03 \\
\hline 2012 & 0,45 & 13.902 .155 & 55.608 .620 & 27,45 \\
\hline 2013 & 0,51 & 14.086 .199 & 54.936 .176 & 27,10 \\
\hline 2014 & 0,48 & 14.003 .441 & 54.613 .420 & 26,57 \\
\hline 2015 & $N D$ & 13.827 .369 & 53.926 .739 & \\
\hline
\end{tabular}

Fonte: CEPAL (2015)e Guilherme (2016).

Referida estabilidade, ou seja, que desde $2006,1 / 4$ da população total do país, em média, recebe o Bolsa Família, pode representar a permanência dos beneficiários na linha da pobreza e/ou a sua alternância entre ambas as linhas, pobreza e extrema pobreza, merecendo a atenção e o aprofundamento sobre tais evidência. Acredita-se que no contexto da realidade brasileira, em que ainda prevalece necessidades mínimas insatisfeitas como a alimentação representada por severa expressão da questão social que é a fome, apesar dos limites apontados em relação ao PBF, trata-se de amplo contingente populacional em situação de indigência, para o qual a transferência monetária representa, muitas vezes, a única fonte de renda para prover a subsistência.

O fato que se coloca em questão é "que a natureza e o nível dos impactos do BF nas famílias beneficiárias são limitados ao atendimento das necessidades imediatas, sem possibilitar a introdução de mudanças mais profundas no padrão de vida dessas famílias" 
(LIMA, 2010, p. 106). Neste sentido, a partir das reflexões desenvolvidas ao longo deste estudo, estima-se colocar em pauta o combate das desigualdades, sob ponto de vista estrutural, o que corresponde ao processo de mudanças na orientação das políticas econômicas, especificamente o paradigma neoliberal que dá sustentação a essas políticas.

\section{Considerações Finais}

É possível referir que as transformações iniciadas nos anos 1990 na abrangência do território brasileiro se materializam mediante severo ajuste estrutural, o qual impõe reformas restritivas no âmbito das políticas de proteção social, com destaque para a seguridade social. Importante destacar que neste intervalo temporal governos de diferentes matizes ideológicos tratam a questão: de 1990-1992 o Presidente Fernando Collor de Mello, de forma mais incisiva dá início ao processo4; no entanto no período do Presidente Fernando Henrique Cardoso ocorre o aprofundamento consistente do ajuste com a privatização de vários segmentos estatais e com a orientação para a sociedade civil no enfrentamento de problemas sociais por meio de estímulos a expansão do Terceiro Setor, o que trará de volta o incentivo às ações de filantropia; na sequência é a vez do Presidente Luiz Inácio Lula da Silva que, não só rompe com esta tendência, mas reorienta o encaminhamento das políticas sociais reforçando o papel do Estado enquanto responsável pelo bem-estar social, embora essa condução ocorra de maneira alinhada a perspectiva da focalização na extrema pobreza e na pobreza pela via do PBF. Também cumpre reter que todas estas manifestações de idas e vindas da atuação do Estado, contraditoriamente ou não ocorrem sob a evidência empírica dos pressupostos do paradigma neoliberal que traduz ampla desregulamentação das relações econômicas e sociais, ampliando níveis de extrema pobreza e pobreza.

Por outro lado, no continente latino-americano, independente do perfil ideológico dos diferentes governos, de modo especial a partir dos anos 2000 são amplamente instituídos Programas de Transferência Condicionada de Renda, a exemplo do programa brasileiro intitulado Bolsa Família, revelando a priorização de uma política social focalizada, em detrimento da perspectiva universal ${ }^{5}$.

\footnotetext{
${ }^{4}$ Após o impeachment do Presidente Collor de Mello, assume o Vice-Presidente Itamar Franco (1992/1994), cujo legado foi o de debelar o processo inflacionário brasileiro e concluir a renegociação do endividamento externo.

${ }^{5}$ Existem evidências, em alguns estudos sobre o tema, que esta proliferação de PTCR configura respostas dos governos aos compromissos assumidos quando dos Objetivos do Milênio.
} 
Conforme as evidências práticas da experiência brasileira, a partir dos dados apresentados e das análises desenvolvidas, é possível concluir que o PBF configura muito mais um meio de manutenção da condição de pobreza do que uma possibilidade de ascensão social dos indivíduos. Por outro lado, cabe destacar a sua importância, visto que as transferências monetárias, ainda que insuficientes, contribuem para a sobrevivência de parcela significativa da população.

Entretanto, considerando a sua principal contradição, há de se destacar que uma das expressivas limitações reporta ao caráter focalizado e restritivo que permeia a sua concepção. Ou seja, tais programas se alinham a uma perspectiva de contrarreforma dos sistemas de proteção social, contribuindo para a reprodução do modo de produção capitalista na medida em que tais reformas, sob a perspectiva crítica, configuram resposta do capital à sua "crise".

Em síntese foi possível explicitar que a predominância dos PTCR - de modo específico o Programa Bolsa Família considerado a principal estratégia governamental de enfrentamento à pobreza - envolve um processo de desmonte do sistema de proteção social brasileiro, com destaque para as políticas que compõem o tripé da seguridade social, já que essas últimas sistematicamente são alvos de processos de contrarreformas viabilizadas pela ideia de mercantilização/privatização da saúde e da previdência, além dos reiterados apelos à solidariedade do terceiro setor no âmbito da assistência social.

\section{Referências}

BEHRING, Elaine Rossetti; BOSCHETTI, Ivanete. Política Social: fundamentos e história. Cortez: São Paulo, 2007.

BRASIL. Lei $n$ o 8.742, de 7 de dezembro de 1993. Dispõe sobre a organização da Assistência Social e dá outras providências. Brasília, DF: Presidência da República, 1993. Disponível em: http://www.planalto.gov.br/ccivil_03/leis//8742.htm. Acesso em: 9 jan. 2016.

BRASIL. Ministério do Desenvolvimento Social e Combate à Fome. Bolsa família. Disponível em: http://mds.gov.br/assuntos/bolsa-familia. Acesso em: 27 jan. 2016 a.

BRASIL. Ministério do Desenvolvimento Social e Combate à Fome. Bolsa família:

transferência de renda e apoio à família no acesso à saúde, à educação e à assistência social. Brasília: Ministério do Desenvolvimento Social e Combate à Fome, 2015a. Disponível em: http://www.mds.gov.br/webarquivos/publicacao/bolsa_familia/Cartilhas/Cartilha_PBF_201 5.pdf. Acesso em: 29 jan. 2016.

BRASIL. Ministério do Desenvolvimento Social e Combate à Fome. Coletânea da legislação basica do Cadastro Único e do Programa Bolsa Família. 3. ed. Brasília: Ministério de 
Desenvolvimento Social, 2017. Disponível em:

http://www.mds.gov.br/webarquivos/publicacao/bolsa_familia/Cadernos/Coletanea_Legisla caoBasica.pdf . Acesso em: 27 jan. 2016.

BRASIL. Ministério do Desenvolvimento Social e Combate à Fome. LOAS anotada: lei orgânica da assistência social. Brasília: Ministério do Desenvolvimento Social e Combate à Fome, 2009. Disponível em:

http://www.mds.gov.br/webarquivos/publicacao/assistencia_social/Normativas/LoasAnota da.pdf. Acesso em: 29 jan. 2016.

BRASIL. Ministério do Desenvolvimento Social e Combate à Fome. Plano Brasil sem miséria: caderno de resultados 2011-2014. Brasília: Ministério do Desenvolvimento Social e Combate à Fome, 2015b. Disponível em:

http://www.mds.gov.br/webarquivos/publicacao/brasil_sem_miseria/cadernodegraficosbs m-35anos.pdf. Acesso em: 28 jan. 2016.

BRASIL. Ministério do Desenvolvimento Social e Combate à Fome. Relatórios de informações sociais: RI Bolsa Família e Cadastro único. 2016b. Disponível em:

http://aplicacoes.mds.gov.br/sagi/Rlv3/geral/relatorio.php\#Visão Geral Brasil. Acesso em: 27 jan. 2016.

CEPAL. División de Desarrollo Social DDS. Base de datos de programas de protección social no contributiva en América Latina y Caribe. 2015. Disponível em:

http://dds.cepal.org/bdptc/. Acesso em: 15 jan. 2016.

DI GIOVANNI, Geraldo. Sistema de proteção social: uma introdução conceitual. In: OLIVEIRA, Marco Antonio (org.). Reforma do Estado e política de emprego. Campinas: IE/UNICAMP, 1998. p. 9-30.

GUILHERME, Rosilaine Coradini. Renda mínima de inserção e transferência condicionada de renda: as (a) simetrias entre União Europeia e MERCOSUL. 2016. 249 f. Tese (Doutorado) Pontifícia Universidade Católica do Rio Grande do Sul, Porto Alegre, 2016. Disponível em: http://repositorio.pucrs.br/dspace/handle/10923/8378. Acesso em: 15 ago. 2019.

IAMAMOTO, Marilda Villela. Serviço social em tempo de capital fetiche: capital financeiro, trabalho e questão social. São Paulo: Cortez, 2008.

LIMA, Valeria Ferreira Santos de Almada. Avaliando o bolsa família: unificação, focalização e impactos. Coordenação de Maria Ozanira Silva e Silva. São Paulo: Cortez, 2010.

MIOTO, Regina Célia Tamaso. Família e políticas sociais. In: BOSCHETTI, Ivanetti (org.). Política social no capitalismo: tendências contemporâneas. São Paulo: Cortez, 2008.

PEREIRA, Potyara A. P. Necessidades humanas: subsídios à crítica dos mínimos sociais. São Paulo: Cortez, 2000.

POLANYI, Karl. A grande transformação: as origens da nossa época. 2. ed. Rio de Janeiro: Elsevier, 2000. 
REIS, Carlos Nelson. Crescimento econômico e pobreza na América Latina: notas sobre uma relação assimétrica. Textos \& Contextos, Porto Alegre, v. 3, n. 1, p. 1-13, 2004. Disponível em: http://revistaseletronicas.pucrs.br/fo/ojs/index.php/fass/article/view/974/754. Acesso em: 14 jan. 2016.

SACHS, Jeffrey. O fim da pobreza: como acabar com a miséria mundial nos próximos 20 anos. São Paulo: Companhia das Letras, 2005.

SILVA; Maria Ozanira Silva e. Caracterização e problematização dos programas de transferência de renda condicionada (PTRC) na América Latina e Caribe. In: SILVA, Maria Ozanira Silva e. Programas de transferência de renda na América Latina e Caribe (coord.). São Paulo: Cortez, 2014.

SILVA; Maria Ozanira Silva; YAZBEK, Maria Carmelita; DI GIOVANNI, Geraldo. A política social brasileira no século XXI: a prevalência dos programas de transferência de renda. São Paulo: Cortez, 2004.

SPOSATI, Aldaiza de Oliveira; BONETTI, Dilséa Adeodata; YASBEK, Maria Carmelita; CARVALHO, Maria do Carmo Brant. Assistência na trajetória das políticas sociais brasileiras: uma questão em análise. Cortez: São Paulo, 1998.

YAZBEK, Maria Carmelita. Pobreza no Brasil contemporâneo e formas de enfrentamento. Serviço Social e Sociedade, São Paulo, n. 11, p. 288-322, abr./jun. 2012. Disponível em: http://www.scielo.br/pdf/sssoc/n110/a05n110.pdf. Acesso em: 13 jan. 2016.

Recebido em: 08.11.2019

Aceito em: 09.06.2020 